\title{
Reading Acquisition Software for Portuguese: Preliminary Results
}

\author{
Ana Sucena*, Ana Filipa Silva, Cristina Garrido, Cátia Marques \\ Research and Intervention Reading Centre, Polytechnic Institute of Porto, Porto, 1800-412, Portugal
}

\begin{tabular}{l} 
A R T I C L E I N F O \\
\hline Article history: \\
Received: 07 May, 2021 \\
Accepted: 15 June, 2021 \\
Online: 19 October, 2021 \\
\hline Keywords: \\
I Read \\
Acquisition \\
Reading \\
Spelling \\
\end{tabular}

\begin{tabular}{l} 
A B S T R A C T \\
\hline The persistent difficulties in reading and spelling acquisition are a risk factor for learning \\
motivation. Play-like intervention tools have been developed to face these difficulties. "I \\
read" is a software that seeks to develop and introduce systematic reading and spelling skills \\
training in a playful and complementary way. This software is intended for children at the \\
beginning of their school journey, as well as for those who reveal reading and/or spelling \\
difficulties. This article intends to present the goals and the structure of this software, as well \\
as the preliminary results of its implementation and game enjoyment with 244 children \\
between 5 and 7 years old. Results indicate that 58\% of the participants completed the \\
activities dedicated to alphabetical decoding, and $42 \%$ were able to reach the last stage of \\
the game, dedicated to orthographic decoding. Regarding the enjoyment with the software, \\
$96 \%$ of the participants classify the games as fun games. In conclusion, training with this \\
software revealed to be beneficial for reading and spelling skills promotion, as well as to \\
increase the overall enjoyment and motivation for learning.
\end{tabular}

\section{Introduction}

Research highlights persistent difficulties in reading acquisition as a key risk factor for school motivation, learning and children's self-esteem [1]. These difficulties lead to long-term negative consequences, such as behavior problems, depression and other mental health issues [2]. If reading disabilities are not early addressed, difficulties tend to generalize to other domains, exposing students to consecutive experiences of failure, thereby diminishing their motivation to learn [3], jeopardizing future knowledge acquisition [4]. In turn, when these difficulties are identified early and lead to a prompt intervention, the likelihood of reversing failure trajectories is very high [5], [6].

Thus, early intervention to face learning difficulties, namely on reading and spelling [7]-[10] is of utmost importance. Early intervention can have an even more ambitious purpose: preventing the child from experiencing learning difficulties, hence the term "at-risk" (of experiencing reading and writing learning difficulties). The risk for retention, school dropout and low motivation decreases with the adoption of early intervention focused on the key competencies for reading acquisition [11]. Phonemic awareness, letter-sound knowledge and decoding skills are the key competencies for successful reading and writing acquisition [11], [12].

\footnotetext{
*Corresponding Author: Ana Sucena, asucena@ess.ipp.pt
}

As a result, the past decade has been witnessing the fast development of information technologies, together with the rapid development of serious games [13]. Serious games consist of entertaining tools with educational purposes, presented as digital games throughout which children are required to overcome numerous obstacles. The serious games primary goal is to contribute to increasing the players' motivation to acquire and expand knowledge and practising skills [13]. Educational aspects are included in the gameplay, which will be acquired and automatized by the players during the gaming process [13]. To ensure effective learning in serious games many aspects are important. Designers are not only faced with the challenge of creating appealing graphics and a compelling narrative, but also with the additional challenge of incorporating suitable pedagogical strategies into their narratives [14].

In sum, serious games are congruently described in the literature as digital games that have an explicit and carefully thought-out educational purpose and are not solely intended for amusement [15], [16]. The development of these types of games, in a motivating, challenging and playful environment has proven to be a more effective tool at conveying knowledge and achieving behavior change [14] than the traditional teaching and learning methods [17], [18]. Serious games also present an opportunity for proactive learning by involving players in an immersive learning experience where they can apply their knowledge, learn from 
experience, and test complex or risky scenarios in a safe and playfull environment.

Player enjoyment is the term used to express the satisfaction perceived when performing tasks and activities that require high levels of concentration and skills in digital games [19]-[21]. Enjoyment is a form of fun that serious games can promote, resulting from the challenges the players face and must be able to overcome to advance in the game [22]. Player enjoyment is an important aspect for educational serious games, as they are commonly introduced to students by professionals responsible for the teaching process who are leading students to play, rather than the students starting to play willingly or through a recommendation from friends. Therefore, promoting player enjoyment can keep them interested in continuing to play along with all the levels, continuing to develop their skills in the contents covered by the game, potentially enhancing the results from the use of these educational tools in specific domains.

The game levels are used to show the progress of users. It is a common practice for serious games to adopt levels to show increasing difficulty and complexity levels. This option is based on shaping - a behaviour changing strategy. Shaping consists of breaking tasks down into small discrete steps and training in a systematic and precise way [23]. This can be linear (e.g., you level up after earning 50 points), or exponential. Creating the levels at the right difficulty and complexity (level balancing) is important to avoid drop-outs. Difficulty can also serve as a way to motivate the users as they passed a specifically difficult level the child gets points and move forward in the game [24]. The different levels give players a direction in order to reach the goal that needs to be achieved. Players have something to accomplish within their overall experience [25].

Due to these features, serious games have been successfully applied in various domains such as medicine, military, or complex processes training, among others; example success-cases include commerce, environment and ecological behaviour, cartography, machine learning, software development, innovation, health and medical issues, tourism, energy, mobility and transportation, accessibility fashion, usability, risk management, marketing [26] and with children with learning disabilities [11].

Serious games have become increasingly popular in education, supporting children with learning disabilities [27]-[32]. It can be used as a tool to reinforce the teaching process and provide enriching learning contexts for its users [26]. Most children with learning disabilities can be successful in reading acquisition with the help of a tutor or a specialized teaching program [33]. Emotional support also plays an important role for these children while dealing with learning disabilities [33]. Several studies have shown that children prefer playing a "fun" computer game than performing a "boring" exercise [34]. The idea is that the user does something useful, for his/her knowledge. If the user has fun, she/he will probably continue to play, achieving the serious goals of the game [34]. Serious games can be a great help in these situations, not substituting, but complementing the work done by therapists [35]. Moreover, improving the life quality of children with learning disabilities has a crucial impact on their learning and future path.
The results of serious games as a tool to intervene with children with learning disabilities are supported by the empirical findings of several studies [36]. There is an increasing demand for innovative and cost-effective evidence-based solutions to the educational challenges faced by teachers and students. Reading related difficulties represent $80 \%$ of the overall learning difficulties [37], which makes it all the more important to invest in developing reading acquisition serious games.

The Graphogame reading promotion software is one of the pioneer's projects regarding serious games in learning acquisition. The Graphogame provides children with training in phoneme awareness, letter-sound and early word decoding training. This play-like software was developed in a research project, originally developed in Finland, then adapted for over 20 language versions (e.g., Finnish [9], [38]-[40]; German [41], [42]; English [12], [43]; Portuguese [11], [48]; Spanish [45]). In this computer game set, the child uses headphones and hears a sound that corresponds to a letter, word or pseudoword, and he/she must select the written option corresponding to the sound.

Recently, a new Portuguese serious game was developed - I Read [46], [47]. This serious game aims to promote phonemic awareness, letter-sound knowledge and decoding. Compared to the Portuguese Graphogame the I Read has a greater focus on lettersound knowledge as well as on spelling tasks. For each set of lettersound, activities are focusing on monosyllabic words (CV and CVC syllabic structure) reading and spelling. The I Read serious game intends to facilitate reading and spelling acquisition in a playful and complementary environment. In this study, we describe the I Read software, along with preliminary results of its implementation on reading and spelling skills, as well as on the player enjoyment levels.

In this study we present the I Read software that aims to practise basic literacy skills, we present the main results of its implementation, as well as, assess the children enjoyment with the game.

\section{Method}

\subsection{Participants}

244 first graders participated in this study, aged between 5 and 7 years old, studying in Portuguese public schools. All children were identified as at risk of experiencing difficulties in reading. None of the participants revealed any sensory, motor or cognitive disturbances according to school registers.

\subsection{Instrument}

The I Read is a recently developed computer software, for reading and spelling training with Portuguese speaking children. I Read [36], [37] focus on the development of the alphabetical principle - training letter-sound and phonemic awareness - and decoding through systematic training, along with different games. This software is intended for children at the beginning of their school path and withchildren at risk of experiencing difficulties in reading acquisition. The I Read can be played on any computer or tablet, with internet access. Each child logs in with a username and password. Information about the game is recorded online, which allows the child to resume the exact game in the next session. 
The general and specific goals of the I Read software are described in table 1 . There are 13 game levels. Between level one and nine, the goal is to promote the alphabetic principle and alphabetic decoding, thus all stimuli correspond to simple graphemes and have simple syllabic structure. Between level 10 and 13, the focus shifts to orthographic decoding, with stimuli composed of complex graphemes and complex syllabic structure.

Table 1: I Read goals

\begin{tabular}{|l|l|}
\hline General goals & Specific goals \\
\hline Simple vocalic grapheme (level 1) & $\begin{array}{l}\text { Phonemic awareness } \\
\text { Letter-sound knowledge } \\
\text { Alphabetical decoding }\end{array}$ \\
\hline Oral diphthongs (level 2 and 3) & $\begin{array}{l}\text { Phonemic awareness } \\
\text { Alphabetical decoding } \\
\text { Spelling decoding }\end{array}$ \\
\hline Nasal diphthongs (level 4) & $\begin{array}{l}\text { Phonemic awareness } \\
\text { Alphabetical decoding } \\
\text { Spelling decoding }\end{array}$ \\
\hline $\begin{array}{l}\text { Simple consonant grapheme } \\
\text { (level 5 to 9) }\end{array}$ & $\begin{array}{l}\text { Phonemic awareness } \\
\text { Letter-sound knowledge } \\
\text { Alphabetical decoding } \\
\text { Spelling decoding }\end{array}$ \\
\hline $\begin{array}{l}\text { Complex consonant grapheme } \\
\text { (level 10 to 13) }\end{array}$ & $\begin{array}{l}\text { Phonemic awareness } \\
\text { Letter-sound knowledge } \\
\text { Spelling decoding }\end{array}$ \\
\hline
\end{tabular}

Within each level, the difficulty increases along with the games. For example, at level five (p, t, s) there are 13 sub-levels.

The $1^{\text {st }}$ and $2^{\text {nd }}$ sub-levels focus on phonemic awareness and letter-sound knowledge training; from the $3^{\text {rd }}$ to the $13^{\text {th }}$ sub-level, the goal shifts to alphabetical decoding. The same difficulty continuum applies to the syllabic length, as words/ pseudowords presented on the initial levels are monosyllabic CV, CVGwhereas two-syllable words/ pseudowords are introduced in more advanced levels - CV.CV, CVG.CV/CV.CVG. Finally, reading tasks precede spelling tasks - from the $3^{\text {rd }}$ until the $8^{\text {th }}$ sub-level the focus is on reading games; spelling games appear from the $9^{\text {th }}$ level.

The narrative behind the software is that of a challenge to discover planets and satellites in a galaxy, along with spatial-like music, intending to contribute to a playful appearance. Each planet represents a level, whereas satellites (around each planet) represent the game sublevels. Each game is presented with a different scenario (e.g., under the ocean; in space; on a submarine) and contains multiple trials. Each trial contains multiple stimuli, always presented along with distractors.

There are two types of game: a) identification/ reading - the child hears a sound corresponding to a letter, word or pseudoword and he/she identifies the orthographic match on the screen; b) spelling - the child hears a word or pseudoword and is required to select and order the constituent letters (presented in the screen, in random order).

In all games, there is a button represented by a loudspeaker, which the child can press whenever he/she needs to hear the target stimulus again. The accuracy feedback is provided immediately after the correct or incorrect answer (through an auditory and visual stimulus). If the answer is inaccurate, the stimulus visually trembles and disappears from the screen, thus reducing the number of stimuli on the screen (until only the right option appears on the screen). The software adapts to the performance of the player, by eliminating the possibility for repeated mistakes. As the child starts improving performance, the number of distractors increases again. It was adopted the errorless learning strategy. This strategy aims to minimize opportunities for errors, increasing the frequency at which the child encounters reinforcement. Minimizing errors also reduces the likelihood that the child engages in challenging behavior [39]. When the child selects the correct answer, a green checkmark appears on the screen (along with a "correct-like" sound). At the end of each game, there is feedback on the game's performance, through the attribution of one to three stars.

I Read can be played in two modes, free or pre-set mode. Thus, it is possible to select specific levels/planets (free mode, designed for the teacher/ adult accompanying the training) or to follow the preset outline (designed for the child playing on her own) by playing the levels in increasing difficulty, with the advantage of the software adaptation to each child learning rhythm [39].

The player enjoyment with the I Read was assessed by asking the players to classify their satisfaction with the game using a three Likert scale using smiles. If the players are very satisfied they answer three smiles, more or less satisfied two smiles and if they are not satisfied one smile.

\subsection{Procedures}

This software was implemented with at-risk first graders. Training occurred 3 to 4 times a week in sessions between 15 to 20 minutes, in a school context, between November and May of 2020, under the supervision of an expert in reading and spelling promotion, with specific training on the software. Each child played individually, on a computer, in a noiseless environment and/or with the use of headphones. Children played in the preset mode, according to their learning pace. The information of each player gaming sessions was recorded, so the child could resume playing at the point where he/she stayed the last time he/she played, on any computer, as long as he/she has access to his/her user name and password.

\section{Results}

The ultimate challenge - playing all the 13 planets and respective satellites up until the last one - was reached by 48 children (15\% of the total children). On average, participants took 18 sessions to reach the final game, with a frequency of play of about once per week.

On a level-by-level analysis, all participants concluded the vowels and diphthongs levels. The percentage decreases when we analyse the alphabetic decoding and the orthographic decoding (respectively, $58 \%$ and $42 \%$ ) (Table 2). 
Table 2: Distribution of participants reaching each level of difficulty

\begin{tabular}{|lll|}
\hline Levels & $\begin{array}{l}\text { Number } \\
\text { Participants } \\
\text { (\%) }\end{array}$ & $\begin{array}{l}\text { Number Participants (\%) by } \\
\text { levels of groups }\end{array}$ \\
\hline 1 & 0 & 0 \\
2 & 0 & \\
3 & 0 & \\
4 & 0 & $142(58.2 \%)$ \\
\hline 5 & $50(20.5 \%)$ & \\
6 & $27(8.6 \%)$ & \\
7 & $21(6.7 \%)$ & \\
8 & $25(7.9 \%)$ & \\
9 & $19(6.03 \%)$ & \\
\hline 10 & $32(10.2 \%)$ & $102(41.8 \%)$ \\
11 & $8(2.5 \%)$ & \\
12 & $14(4.4 \%)$ & \\
13 & $48(15.2 \%)$ & \\
\hline
\end{tabular}

Regarding player enjoyment, 233 (95.5\%) participants found fun to play the games (Figure 1).

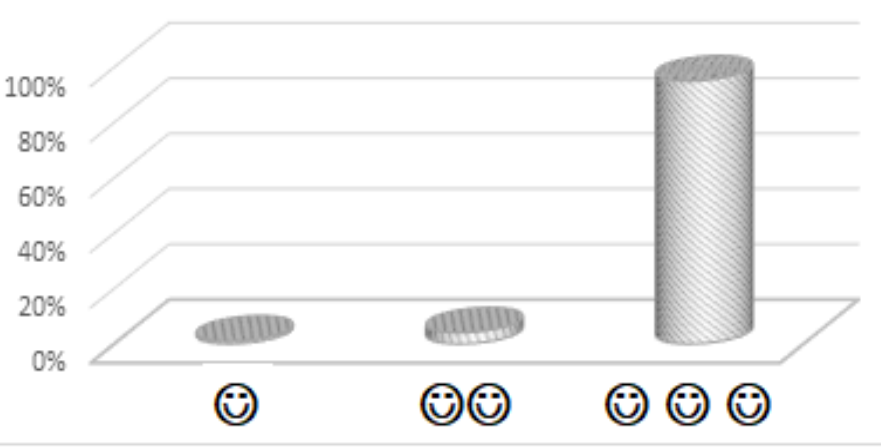

Figure 1: Player’s enjoyment

\section{Discussion}

Ensuring literacy acquisition in early grades is a fundamental investment. In this study, we intended to (i) present the I Read software that aim to practice basic literacy skills, (ii) the main results of its implementation as well as (iii) children enjoyment with the game. The development of serious games has a large impact on education, prompting the need for upgraded policy making, curriculum development, and teacher training. Providing teachers and educational technicians with research technology empowers them to take their places as qualified experts and advisers that policymakers need for making informed choices for better education quality [4].

The results of this study show that all participants managed to finish the first stage, focused on the Alphabetic Principle vowels, diphthongs, and oral and nasal diphthongs. Around 60\% of children reached the second stage - focused on alphabetic decoding. These are promising results, as these students finish the first grade dominating the alphabetic decoding. Having started the $1^{\text {st }}$ grade with weak pre-reading skills, these children conclude the $1^{\text {st }}$ grade with reasonable reading skills, thus moving on to the $2^{\text {nd }}$ grade without the at-risk label. The I Read software positively impacts the attentional and motivational level [11], which are, for at-risk children, often negatively affected by the growing awareness of their difficulties [8].

There is, yet, potential to increase the average results. Regarding the last stage - focusing on orthographic decoding - the results are modest. This stage was attained by $42 \%$ of the children and only $15 \%$ managed to finish all games. It is important to develop strategies to increase the percentage of children who finish all games. One possible strategy could be to count on the support of an adult during the time when the child is playing I Read. Complementary activities with the supervision of an adult in order to promote orthographic decoding are also an important strategy to help children facing difficulties. The results indicate that children at risk for reading acquisition difficulties benefit from a remedial reading intervention that is enriched with the use of the I Read software at the very beginning of the first grade.

Regarding player enjoyment, the results confirm the playful nature of the software as an effective tool to intervene with children with learning disabilities. These results also encourage us to continue the intervention, in particular with children who are facing difficulties. The focus of the software on phonemic awareness, letter-sound knowledge and decoding skills, which are the key competencies for successful reading and writing acquisition [8], [9], [11], [12], [16] along with the playful environment, proved to be highly beneficial to promote reading acquisition. Thus, a simple learning game can provide learning and playful opportunities for struggling readers.

In future studies, it is important to test the impact of the software in terms of effective learning, creating two groups of atrisk children - an intervention group that plays regularly and a comparative group that does not use the software. Also, in order to understand the role of the teacher's training in the application for the software, in future studies this variable should be controlled. Future studies could also include a thorough analysis of the intervention process to better understand the evolution of participants from session to session, along with the teachers' perspective regarding the software efficacy and a follow-up study of the participants, thus contributing for this educational tool to become even more effective for teachers and students. Since literacy is closely tied to social and economic development, quality research on this subject, along with its dissemination play a key role in the maintenance and increase of economic and social increase. Adaptations of the I Read to different Portuguese speaking countries and for other languages could be an important step for the worldwide promotion of reading acquisition with atrisk children, by focusing the training on the very specific skills, highly associated with success in reading acquisition.

\section{Conclusion}

Successful reading and writing acquisition is associated with an overall and long-lasting good performance in the educational, social and professional path. In the same vein, any impairment in the early reading acquisition can negatively affect the life trajectory in general. To intervene with at-risk children regarding reading acquisition is known to have high economic revenue, as a successful reading acquisition increases the odds for broad school success. Losing one year in the labour force (after school retention 
caused by learning difficulties) corresponds to a loss of around $\$ 80,000$, on an estimate for a college-educated male working full time and year-round, retiring at age 67 in the USA [42].

Serious games are highly effective on reading acquisition as well as, on broader terms, on the learning process. Serious games are a strong complement to more conventional instruction methods, with a higher capacity for motivating children in result of the gamelike and technology-like appearance. Research has shown that serious games have the potential to prevent and remediate reading difficulties. The use of the playful-like I Read software, focusing on reading and spelling skills, has proven to be an important complementary tool for early intervention with at-risk children. It is the author's belief (and expectation) that by captivating the children's attention for reading-related training, the I Read will play an important role in the foundations of the overall enjoyment and motivation for learning.

\section{Conflict of Interest}

The authors declare no conflict of interest.

\section{Acknowledgment}

This work was supported by European Horizon 2020, under OPERAÇÃO NORTE-08-5266-FSE349 000095.

\section{References}

[1] R. Lovio, A.Halttunen, H.Lyytinen, R Näätänen, T. Kujala, "Reading skill and neural processing accuracy improvement after a 3-hour intervention in preschoolers with difficulties in reading-related skills,” Brain Research, 11, 42-55, 2012, doi:10.1016/j.brainres.2012.01.071

[2] A. M.Undheim, L.Wichstrøm, A. M.Sund, "Emotional and behavioral problems among school adolescents with and without reading difficulties as measured by the youth self-report: a one-year followup study," Scand. J. Educ. Res. 55, 291-305, 2011, doi: 10.1080/00313831.2011. 576879

[3] H. Lyytinen, J.Erskine, "Early identification and prevention of reading problems," Encyclopedia on Early Childhood Development, 1-5, 2016. Retrieved from http://www.childencyclopedia.com/documents/LyytinenErskineANGxp.pdf

[4] S.Raspin, R.Smallwood, S.Hatfield, L.Boesley, "Exploring the use of the ARROW literacy intervention for looked after children in a UK local authority," Educational Psychology in Practice, 35(4), 1-13, 2019, doi:10.1080/02667363.2019.1632172

[5] M. Hall, M. Burns, "Meta-analysis of targeted small-group reading interventions," Journal of School Psychology, 66(1), 54-66, 2018. doi:10.1016/j.jsp.2017.11.002

[6] H. Lyytinen, "New Technologies and interventions for learning difficulties: Dyslexia in Finnish as a case study". In Foresight Mental Capital and Wellbeing Project: The Government Office for Science. Government Office for Science, London: UK, 2008.

[7] P.Hatcher, C.Hulme, M.Snowling, "Explicit phoneme training combined with phonic reading instruction helps young children at risk of reading failure" Journal of Child Psychology and Psychiatry, 45(2), 338-358, 2004.

[8] U. Richardson, H. Lyytinen, "The GraphoGame method: The theoretical and methodological background of the technology-enhanced learning environment for learning to read", Human Technology, 10, 39-60, 2014. doi:10.17011/ht/urn.201405281859.

[9] N.L. Saine, M.K.Lerkkanen, T.Ahonen, A.Tolvanen, H.Lyytinen, "Computer-assisted remedial reading intervention for school beginners at risk for reading disability”, Child Development, 82, 1013-28, 2011doi:10.1111/j.1467-8624.2011.01580.x

[10] H. Wimmer, H.Mayringer, "Dysfluent reading in the absence of spelling difficulties: A specific disability in regular orthographies", Journal of Educational Psychology, 94(2), 272-277, 2002.

[11] A.Sucena, , J.Cruz, F.L.Viana, A.F.Silva, “Graphogame português alicerce: software de apoio a crianças disléxicas. In M. J. Gomes, A. J. Osório \& L. Valente (Eds.), Atas da IX Conferência Internacional de TIC na Educação (pp. 396-405). Braga: Universidade do Minho/Centro de Competência em TIC na Educação, 2015.

[12] F.E. Kyle, J. Kujala, U. Richardson, H. Lyytinen, U.Goswami, “Assessing the effectiveness of two theoretically motivated computer-assisted reading interventions in the United Kingdom: GG rime and GG phoneme”, Reading Research Quarterly, 48, 61-76, 2013, doi:10.1002/rrq.038.

[13] Y.Zhonggen, "A Meta-Analysis of Use of Serious Games in Education over a Decade. Hindawi" International Journal of Computer Games Technology 2019, 4797032, doi:10.1155/2019/4797032

[14] O.Troyer, F.Van Broeckhoven, , J.Vlieghe, "Linking serious game narratives with pedagogical theories and pedagogical design strategies," J Comput High Educ 29, 549-573, 2017, doi:10.1007/s12528-017-9142-4.

[15] C.C. Abt Serious Games University Press of America, 1987.

[16] M.A. Khenissi, F. Essalmi, M. Jemni, "Comparison between serious games and learning version of existing games," Procedia - Social and Behavioral Sciences, 191, 487-494, 2015, doi:10.1016/j.sbspro.2015.04.380.

[17] N. Bäulke, M.Eckerlein, M. Dresel, "Interrelations between motivational regulation, procrastination and college dropout intentions" Unterrichtswissenschaft, 46(4) 461-479, 2018， doi: 10.1007/s42010-0180029-5.

[18] Y. Du, S. Chaaban, A.M. Sabah, L. Al-Thani, Wang, Active learning engagement in teacher preparation programmes-A comparative study from Qatar, Lebanon and China Asia Pacific Journal of Education, 40(3), 283-298, 2020, doi:10.1080/02188791.2020.1717436

[19] M. Csikszentmihalyi, "Finding flow: the psychology of engagement with everyday life," Psychol. Today, 1-7, 1997.

[20] P. Sweetser, P. Wyeth Gameflow, "A model for evaluating player enjoyment in games," Comput. $\quad$ Entertain., 3 (2005), 13, doi:10.1145/1077246.1077253.

[21] J. Almeida, L. Machado, "Design requirements for educational serious games with focus on player enjoyment," Entertainment Computing, 38(100413), 2021.

[22] M. Prensky, "Digital game-based learning," Comput. Entertain., 1, 1-21, 2003.

[23] M. Spreckley, R. Boyd, "Efficacy of Applied Behavioral Intervention in Preschool Children with Autism for Improving Cognitive, Language, and Adaptive Behavior: A Systematic Review and Meta-analysis", The Journal of Pediatrics, 2019, doi:10.1016/j.jpeds.2008.09.012

[24] V.Insley, D. Nunan, "Gamification and the online retail experience," International Journal of Retail \& Distribution Management, 42(5), 340-351, 2014, doi:10.1108/IJRDM-01-2013-0030

[25] L.M. Lubbe, C.Gerritsen, M. Klein, K. Hindriks, "Empowering vulnerable target groups with serious games and gamification," Entertainment Computing, 38(100402), 1-27, 2021, doi 10.1016/j.entcom.2020.100402

[26] Baptista, G., Oliveira, T., "Gamification and serious games: A literature metaanalysis and integrative model", Comput. Hum. Behav., 92, 306-315, 2019. doi:10.1016/j.chb.2018.11.030

[27] M. Ronimus, K. Eklund, J. Westerholm, R. Ketonen, H. Lyytinen, "A mobile game as a support tool for children with severe difficulties in reading and spelling", Journal of computer assisted learning, 36, 1011-1025, 2020, doi: 10.1111/jcal.12456.

[28] M. Niemelä, T. Kärkkäinen, S. Äyrämö, M. Ronimus, U. Richardson, H. Lyytinen, "Game learning analytics for understanding reading skills in transparent writing systemritish", Journal of Educational Technology, 51(6), 2376-2390, 2020. doi:10.1111/bjet.12916

[29] K. Khowaja, S. Salim, "A framework to design vocabulary-based serious games for children with autism spectrum disorder (ASD)", Universal Access in the Information Society 19, 739-781, 2020 doi:10.1007/s10209-01900689-4.

[30] K.D. Godinez, L.S. Gaytán-Lugo, P.A. Alcaraz-Valencia, Rocío Maciel Arellano, "Evaluation of a Low Fidelity Prototype of a Serious Game to Encourage Reading in Elementary School Children", CLIHC '17, November 8-10, 2017, doi:10.1145/3151470.3156640.

[31] S. Serret, S. Hun, S. Thümmler, P. Pierron, A. Santos, J. Bourgeois, F Askenazy, "Teaching Literacy Skills to French Minimally Verbal SchoolAged Children with Autism Spectrum Disorders with the Serious Game SEMA-TIC: An Exploratory Study", Frontiers Psychology, 8(1523), 2017, doi: 10.3389/fpsyg.2017.01523.

[32] J.M. Thomson, N. Foldnesb, P.H. Uppstadc , M. Njåc , O. J. Solheimc , K Lundetræ, "Can children's instructional gameplay activity be used as a predictive indicator of reading skills?", Learning and Instruction, 668, 101348, 2020 doi:10.1016/j.learninstruc.2020.101348.

[33] A. J. Alcázar, E. Venegas, S. Criollo, S.L. Mora An Approach to Accessible 
Serious Games for People with Dyslexia Sustainability 2021, 13, 2507. doi:10.3390/su13052507.

[34] O. Gaggi, C. E. Palazzi, M. Ciman, G. Galiazzo, S. Franceschini, M. Rufino, S. Gorgi, A. Facoetti, Serious Games for Early Identification of Developmental Dyslexia, Comput. Entertain 15, 2, Article 4 (February 2017), 1-24. doi:10.1145/2629558.

[35] R.M. Tomé, J.M. Pereira, M. Oliveira, "Using serious games for cognitive disabilities". In Proceedings of the International Conference on Serious Games Development and Applications, Berlin, Germany, 9-10, October 2014.

[36] M. J. Dondlinger, "Educational video game design: A review of the literature", Journal of Applied Educational Technology, 4(1), 21-31, 2007.

[37] S. Shaywitz, "Entendendo a dislexia: um novo e completo programa para todos os níveis de problemas de leitura", Porto Alegre: Artmed. 2006.

[38] N.L. Saine, M.K. Lerkkanen, T.Ahonen, A. Tolvanen, H. Lyytinen, "Predicting word-level reading fluency outcomes in three contrastive groups: Remedial and computer-assisted remedial reading intervention, and mainstream instruction”, Learning and Individual Differences 20, 402-414, 2010 doi:10.1016/j.lindif.2010.06.004

[39] V. Markham, A. Giles, G. Davies, V. Adshead, G. Tamiaki, R. May, Applications of within-stimulus errorless learning methods for teaching discrimination skills to individuals with intellectual and developmental disabilities: A systematic review", Research in Developmental Disabilities, 97, 103521, 2020, doi: 10.1016/j.ridd.2019.103521

[40] M.Ronimus, H.Lyytinen, "Is school a better environment than home for digital game-based learning? The case of GraphoGame". Human Technology, 11(2), 123-147, 2015 doi:10.17011/ht/urn.201511113637

[41] S.Brem, S. Bach, K.Kucian, J. V. Kujala, T. K.Guttorm, E. Martin, et al."Brain sensitivity to print emerges when children learn letterspeechbsound correspondences", Proc. Natl. Acad. Sci. U.S.A. 107, 79397944, 2010, doi:10.1073/pnas.0904402107

[42] S. Bach, U. Richardson, D. Brandeis, E. Martin, S. Brem, "Print-specific multimodal brain activation in kindergarten improves prediction of reading skills in second grade”. NeuroImage, 82, 605-615, 2013. doi: 10.1016/j.neuroimage.2013.05.062

[43] J.Worth, J. Nelson, J. Harland, D. Bernardinelli, B. Styles, "GraphoGame Rime: Evaluation report and executive summary", Slough, UK: National Foundation for Educational Research, 2018.

[44] A. Sucena, A. F.Silva, F.L.Viana, "Intervenção precoce nas dificuldades de aprendizagem da leitura com recurso ao software Graphogame”, Revista Digital do Programa de Pós-Graduação em Letras da PUCRS Porto Alegre, 9(2), 200-212, 2016.

[45] R. Rosas, J.P.Escobar, M.P. Ramírez, A.Meneses, A. Guajardo, "Impact of a computer-based intervention in Chilean children at risk of manifesting reading difficulties”, Infancia y Aprendizaje, 40(1), 158-188, 2017. doi:10.1080/02103702.2016.1263451

[46] A. Sucena, Eu Leio, Escola Virtual, 2015. Retrived from https://www.escolavirtual.pt/Pagina-Especial/euleio.htm

[47] A. Sucena, C. Marques, A.F. Silva, A. Ramalho, R. Machado, R. Santos, C. Santos, C. Garrido, H. Freitas, I. Santos, I. Rangel, M. J. Mata, "I Read: Reading and writing skills promotion software". In P. Arantes, \& J. V. Sá (Eds.), ARTECH 2019 Proceedings of the: 9th International Conference on Digital and Interactive Arts. Braga: Portugal, 2019. ISBN 978-1-4503-72503

[48] A. Sucena, J.F. Carneiro, M.T. Restivo, "Serious games for reading acquisition: A tentative prototype", Teaching and Learning in a Digital World, 2, 686-692, 2018. doi:10.1007/978-3-319-73204-6_75 